University of Rhode Island

DigitalCommons@URI

Open Access Master's Theses

2014

\title{
INFLUENCE OF A WITHIN MEAL EATING RATE INTERVENTION ON OVERALL DIET QUALITY IN OVERWEIGHT AND OBESE WOMEN
}

Sean C. Krueger

University of Rhode Island, seanckrueger@gmail.com

Follow this and additional works at: https://digitalcommons.uri.edu/theses

\section{Recommended Citation}

Krueger, Sean C., "INFLUENCE OF A WITHIN MEAL EATING RATE INTERVENTION ON OVERALL DIET QUALITY IN OVERWEIGHT AND OBESE WOMEN" (2014). Open Access Master's Theses. Paper 333. https://digitalcommons.uri.edu/theses/333

This Thesis is brought to you for free and open access by DigitalCommons@URI. It has been accepted for inclusion in Open Access Master's Theses by an authorized administrator of DigitalCommons@URI. For more information, please contact digitalcommons-group@uri.edu. 
INFLUENCE OF A WITHIN MEAL EATING RATE INTERVENTION ON OVERALL DIET QUALITY IN OVERWEIGHT AND OBESE WOMEN

BY

SEAN C. KRUEGER

\begin{abstract}
A THESIS SUBMITTED IN PARTIAL FULFILLMENT OF THE
REQUIREMENTS FOR THE DEGREE OF

MASTER OF SCIENCE
\end{abstract}

IN

NUTRITION AND FOOD SCIENCES

UNIVERSITY OF RHODE ISLAND 


\section{MASTER OF SCIENCE THESIS}

OF

SEAN C. KRUEGER

APPROVED:

Thesis Committee:

$\begin{array}{ll}\text { Major Professor: } & \text { Kathleen Melanson } \\ & \text { Geoffrey Greene } \\ & \text { Donna Schwartz-Barcott }\end{array}$

Nasser H. Zawia

DEAN OF THE GRADUATE SCHOOL

UNIVERSITY OF RHODE ISLAND 


\begin{abstract}
Background: Improved diet quality has been identified as a key factor in improving longevity and quality of life. Behavior change interventions seeking to influence diet quality and limit obesity often focus on caloric restrictions and quantities of foods consumed. No current interventions have focused solely on the act of eating, despite initial research that suggests that pace at which food is consumed during a meal may be influential.
\end{abstract}

Objective: The objective of this study is to evaluate relationships between withinmeal eating rate and diet quality, and the influence of participation in an eating rate intervention on diet quality.

Methods: This study is a secondary data analysis utilizing data from the Eating Pace Instruction Classes (EPIC) I Study. Participants included 22 females ages 18 to 24 years with a Body Mass Index (BMI) of $31.8+2.6 \mathrm{~kg} / \mathrm{m}^{2}$. The study used a pre-test post-test design with randomized equivalent treatment and non-treatment control groups. The treatment group participated in a five week intervention consisting of weekly one-on-one coaching sessions focusing on techniques to help participants decrease their within-meal eating rates. Relationships between eating rate and diet quality were assessed by first using laboratory measured eating rate at baseline and post intervention for both groups, and 24-hour dietary recalls to assess dietary quality at these time points. Diet quality was assessed by Alternative Healthy Eating Index (AHEI) scores. Pearson Correlations were used to assess relationships between diet quality and eating pace at baseline. Independent Samples t-tests and one way Analysis of Variance (ANOVA) were used to evaluate potential differences between treatment and control groups post intervention. 
Results: There was no relationship between eating pace and diet quality at baseline ( $\mathrm{r}$ $=0.26, p=3.23$ ). Although the intervention was successful in decreasing eating rate $(\mathrm{F}=13, \mathrm{p}<0.001)$, there was no effect on diet quality $(\mathrm{F}=0.3, \mathrm{p}=0.91)$. In this study, an eating pace intervention that reduced eating rate had no influence on diet quality. Future research should explore combining eating rate instruction with nutrition education to increase diet quality and decrease chronic disease risk. 


\section{ACKNOWLEDGEMENTS}

I am tremendously grateful to Dr. Kathleen Melanson for guidance, patience, support, and insight offered throughout this process and my graduate career. Comments and contributions from Dr. Geoffrey Greene substantially enhanced and guided this project. Committee members Dr. Donnna Schwartz-Barcott and Dr. Darren Beck generously offered their time and insights, resulting in a substantially improved outcome. I am grateful to the scholarship and contributions of Carolyn Matsumoto and Jennifer Arts to the EPIC studies; their efforts facilitated the completion of this project. I am also grateful to my wife, Kristin, and daughter Nina for the support throughout this process. 


\section{Preface}

This thesis was written to comply with the University of Rhode Island graduate school Manuscript Thesis Format. This thesis contains one manuscript paper entitled "Influence of a Within Meal Eating Rate Intervention on Overall Diet Quality in Overweight and Obese Women” by Sean C Krueger, Kathleen Melanson, and Geoffrey Greene. This manuscript has been written in a form suitable for publication in the Journal of Nutrition Education and Behavior. 


\section{TABLE OF CONTENTS}

ABSTRACT ii

ACKNOWLEDGEMENTS iv

PREFACE V V

TABLE OF CONTENTS vi

LIST OF TABLES vii

THESIS: Influence of a Within Meal Eating Rate Intervention on Overall Diet Quality in Overweight and Obese Women

$\begin{array}{ll}\text { Publication Status } & 1\end{array}$

$\begin{array}{ll}\text { Abstract } & 2\end{array}$

Introduction 3

Method 5

$\begin{array}{ll}\text { Study Procedures } & 6\end{array}$

Eating Rate \& Dietary Quality $\quad 8$

$\begin{array}{ll}\text { Discussion } & 9\end{array}$

$\begin{array}{ll}\text { Literature Cited } & 12\end{array}$

$\begin{array}{ll}\text { Tables } & 16\end{array}$

APPENDICES

APPENDIX A: Review of Literature 19

APPENDIX B: Test Day Meal Instructions 32

APPENDIX C: Additional Tables 39

APPENDIX D: Bibliography 38 


\section{LIST OF TABLES}

Table 1: Mean Demographic \& Macronutrient Values by Group at Baseline

Table 2: Analysis of Variance between groups for Diet Quality and Eating

Rate following the Eating Pace Instruction Classes intervention

Table 3: Analysis of Variance between groups for Macronutrient and additional intake values.

Table 4: Study Timeline

Table 5: Intervention Overview

Table 6: Intake Between Groups Post Intervention

Table 7: One Way ANOVA between intervention and control group post Intervention 
Influence of a Within Meal Eating Rate Intervention on Overall Diet Quality in Overweight and Obese Women

Sean C. Krueger, Geoffrey Greene, and Kathleen Melanson

Manuscript prepared for submission to the Journal of Nutrition Education and

Behavior 


\section{Manuscript Abstract}

Objective: This study evaluates relationships between within-meal eating rate and diet quality and the influence of participation in an eating rate intervention on diet quality.

Design: This is a secondary data analysis utilizing data from the Eating Pace Instruction Classes (EPIC) I Study using a pre-test post-test design with randomized equivalent treatment and non-treatment control groups.

Participants: 22 females ages 18 to 24 years with a mean Body Mass Index (BMI) of $31.8+2.6 \mathrm{~kg} / \mathrm{m}^{2}$

Main Outcome Measures: diet quality calculated using the Alternative Healthy Eating Index (AHEI) based on three 24 hour recalls at both pre and post intervention and eating rate (kcal/minute) assessed using a standardized meal and a universal eating rate monitor.

Analysis: This study utilized Pearson Correlation and Repeated Measures ANOVA.

Results: There was no relationship between eating pace and diet quality at baseline ( $\mathrm{r}$ $=0.26, \mathrm{p}=3.23$ ) was found. Although the intervention was successful in decreasing eating rate $(F=13, p<0.001)$, there was no effect on diet quality $(F=0.3, p=0.91)$.

Conclusions and Implications: In this study, an eating pace intervention that reduced eating rate had no influence on diet quality. Future research should explore combining eating rate instruction with nutrition education to increase diet quality and decrease chronic disease risk.

Keywords: diet quality, eating pace, AHEI, obesity 


\section{Introduction}

The relationship between diet quality and chronic disease risk has been empirically demonstrated [1]. Studies attribute the rise in cardiovascular disease (CVD), stroke, diabetes, and osteoarthritis to increases in obesity, and identify poor diet quality as a primary causal factor in this increase in obesity [2]. Reductions in major risk factors such as obesity and poor diet quality have been demonstrated to decrease CVD mortality [3]. One strategy for improving diet quality is increasing awareness of how and what we eat. Traditional weight loss diets have poor long term outcomes [4]. Shifting the focus to how and what food is consumed may improve dietary quality and body weight in the long term [2].

Diet quality is a general term used to reflect overall quality of food intake [1]. The Healthy Eating Index (HEI) is a validated measure of diet quality [5]. Individual food records are coded into a dietary intake database after review with the participant to ensure accuracy [5]. Healthy Eating Index scores are calculated based on 10 components: grain consumption, vegetable consumption, fruit consumption, milk consumption, total fat intake, saturated fat intake, cholesterol intake, sodium intake, and dietary variety with scores ranging from 0 to 10 for each component [5]. The Alternative Healthy Eating Index (AHEI) is an expansion of this index and additionally considers the ratio of monounsaturated fatty acid and polyunsaturated fatty acids to saturated fats, and the amount of red meat in the diet [6-8].

Over 35\% of college students are overweight $[9,10]$. Seventy percent of overweight adolescents will remain overweight as adults [11]. Diet quality, assessed 
by the healthy eating index (HEI) and alternative healthy eating index (AHEI) is a key factor in obesity [12-14]. The Framingham Offspring and Spouse Study, followed 1,265 women, ages 25 to 71 with no CVD risk over a 16 year period and found a substantial influence of diet quality measured by AHEI on the risk of becoming overweight or obese [2]. Another study found that AHEI predicted both total mortality and CVD, cancer and inflammatory-related mortality [15]. Further studies found that the AHEI is associated with lowered risk of chronic disease, diabetes, CVD, cancers including colorectal and estrogen receptor negative breast cancer, and cardiovascular and total mortality [7, 16-19]. The cumulative research suggests that diet quality plays an important role in limiting weight gain and the associated health risks including chronic disease and increased risk of mortality in women of all ages.

No current interventions related to diet quality have focused on eating rate. A study of Japanese dietetic students identified significant relationships between eating rate, BMI, total energy intake, and carbohydrate intake [24]. Faster eating rates have been associated with increased Homeostasis Model of Assessment - Insulin Resistance (HOMA-IR) $\mathrm{p}<0.01$ for women after controlling for age and other factors [20]. Further, eating rate in women had been identified as being associated with slow eating rate was associated with lower BMI and fast eating rate associated with higher BMI controlling for lifestyle and energy intake [20].

The rationale that slower eating rate is associated with higher diet quality is supported by several studies. A study examining the eating rate of 50 common foods demonstrated that high fiber unprocessed foods were associated with slower eating rates [21]. Sensory cues of satiation are inhibited with faster eating rates; responses to 
changes in the energy density of consumed foods are also inhibited by eating quickly [22]. Eating quickly may impact the satiety cascade, characterized by delay in response to change in physical volume and in metabolic pathways [23].

The limited evidence above suggests that slower eating rates may be associated with higher diet quality. This study is a first step in identifying whether an intervention targeting within-meal eating behaviors influences diet quality in overweight and obese females. The purpose of this study is to determine if (1) an association between eating rate and diet quality exists cross-sectionally, and (2) if one-on-one instructional classes teaching techniques for slow within-meal eating rates improves diet quality measured using the AHEI.

\section{Method}

This study is a secondary data analysis of the Eating Pace Instruction Classes (EPIC) intervention. The EPIC study used a pre-test post-test design with subjects randomized to treatment and non-treatment control groups. The treatment group participated in a five week intervention consisting of weekly one-on-one coaching sessions focusing on techniques to help participants decrease their within meal eating rate. The control group was not contacted during the 5 weeks. A Universal Eating Monitor measured eating rate at baseline and post intervention for both groups, and three multiple-pass 24-hour dietary recalls assessed dietary quality at these time points. This study was approved by the University of Rhode Island (URI) Institutional Review Board and participants signed informed consent documents

\section{Study Population}


The study population included 22 females, ages $18-24$ years, recruited at URI. Participants were required to have a body mass index (BMI) between 27 and $37 \mathrm{~kg} / \mathrm{m}^{2}$ and were all self-rated as medium paced eaters based on a screening questionnaire. Exclusion criteria included participation in a current weight loss plan or diet, smoking, pregnancy, lactation, and caffeine dependency, and conditions or medications that would affect weight loss or appetite assessed through the screening questionnaire. Overall attrition was low, with one participant dropping out for lack of interest in the control group, such that 23 subjects were recruited and 22 completed. Participants received $\$ 80$ for study completion.

Participants were recruited throughout the URI campus and surrounding areas. Class announcements in introductory and large lecture courses, flyers distributed on cars in parking lots and hung on walls in the dorms and academic buildings, advertisements placed in the URI campus paper, and television ads on the local access university program, which runs in the dorms and dining halls, and recruitment booths, were used as recruiting strategies. One participant was obtained by word of mouth.

\section{Study Procedures}

At the first appointment, participants read and signed informed consent forms, then were randomized into treatment or control groups on an alternating basis, starting with a coin flip. All laboratory testing was conducted with one participant at a time. Participants were screened and instructed on study procedures and consumed a standard breakfast as a preload meal. Participants were then asked to void their bladder before anthropometric measurements were taken. 
Height was measured to the nearest millimeter using a wall

mounted stadiometer (Seca 222). Weight was measured to the nearest .25 pound using a balance beam scale (Detecto model 3P70), and converted to kilograms. Waist circumference was measured using a Gulick fiberglass tape measure with a tensomitor, level from front to back using the navel as reference (Patterson Medical, Mount Joy, PA). BMI was calculated using weight in kilograms/height in meters squared.

After anthropometric measures, participants ate a standardized laboratory ad libitum pasta lunch [35] during which their eating rate was covertly monitored using a Universal Eating Monitor (UEM). Eating rate was calculated as kcalories/minute. Ad libitum water was also provided, and amounts consumed were determined by weighed differences using an Ohaus Adventurer ARC120 scale. Participants were instructed to eat until the point of comfortable satiation and no indication of eating rate or any other behavioral recommendations were made. Participants remained in the lab for 60 minutes after meal completion.

A multi-pass 24hr food recall was then conducted using Minnesota Nutrition Data System for Research software (NDS-R version 2.6, Food Database 6A, Nutrient Database 23; Nutrition Coordinating Center, University of Minnesota, Minneapolis, MN, USA). Food models and household measures were used to guide subjects with careful attention paid to food types. Two additional $24 \mathrm{hr}$ recalls were later conducted by phone, with a portion size estimator handbook [24]. A total of three 24hr recalls were taken; one recall reflected a weekend day and two recalls reflected weekday intakes. 3-day averages were used to calculate diet quality. 


\section{Intervention}

All participants randomized into the intervention group began the intervention within one week of their test meal. The intervention did not address food types or amounts, only instructions on how food should be consumed. The intervention lasted a total of five weeks. All weekly classes were conducted one-on-one and lasted between 20 and 30 minutes each. Participants were assigned one of two coaches and met exclusively with that coach for the duration of the intervention.

\section{Dietary Quality}

All 24hr food recalls were collected and reviewed using the Nutrient Database System for Research (NDS-R) following validated procedures, and participant’s 3-day average was coded into AHEI measures using established protocols [7].

SPSS version 19.0 (2010, IBM Corporation, Armonk, NY) as used for statistical analysis. Eating rate and diet quality data were normally distributed. At baseline, the association between participants’ laboratory eating rate and diet quality was examined using Pearson's correlations. Repeated Measures ANOVA was used to assess differences in diet quality and eating rate between groups over time. Acceptance of significance was set as $\mathrm{p}<0.05$.

\section{Eating Rate and Diet Quality}

Twenty three females, ages 18-28 (20 \pm 2.58 years), completed baseline measurements and the initial test meal and 22 completed post intervention measurements. There was no difference in demographic variables between groups (12 intervention participants and 10 control participants). There was no significant association demonstrated between eating rate and diet quality using Pearson's Correlation $(r=0.26, p=0.23)$. 
The Repeated Measures ANOVA demonstrated a significant time by group interaction for eating rate $(\mathrm{F}=12.97, \mathrm{p}=0.02)$ with a large effect size (Eta Squared 0.393) [25]. There was no effect of the intervention on dietary quality measured by the AHEI (F = 0.3, $\mathrm{p}=0.865)$ or modified AHEI excluding alcohol and multivitamin components ( $\mathrm{F}$ $=0.013, \mathrm{p}=0.909)$.

Pearson's correlations were also run on each AHEI component in relation to eating rate (kcalories per minute) at baseline. Eating rate was demonstrated to be significantly associated $(\mathrm{p}<0.05)$ with fruit $(\mathrm{r}=0.42)$, transfats $(\mathrm{r}=0.52)$, and alcohol $(r=-0.46)$. Repeated Measures ANOVA was also used to examine the time by group interaction for each of the AHEI components and major macronutrients, yielding no statistically significant results (Table 3).

\section{Discussion}

Despite a significant effect on eating rate, this study found no relationship between diet quality and eating rate. As a secondary data analysis, this study was limited by the temporal period and number of subjects. The number of participants was determined to detect and effect on eating rate based on previous eating rate studies. Using post-hoc data values for diet quality derived in this study, a power analysis using the GLIMMPSE (study design tool calculation indicated that 34 subjects per group would yield a sufficiently large sample for alpha (probability of a type 1 error) of 0.05 [27].

Use of a different measure of diet quality may also provide insight into any potential relationship between diet quality and eating rate. The AHEI is a composite diet quality index that includes alcohol consumption and multivitamin intake in the 
diet quality score, although an alternate calculation of AHEI excluding these factors did not affect results. Some components of the AHEI are scored with high values for adequate intake. This makes it possible for high consumption of some foods, for example fruits and vegetables to occur in a way that is not reflected in overall calories. Few components of the AHEI correlated significantly with eating rate, and those that did in this study offer little insight for intervention. Two significant associations, fruit and alcohol, may in part be explained by the measurement difficulties discussed above. Foods high in transfats typically contain little fiber and are able to be consumed more quickly perhaps explaining the other significant positive association ( $\mathrm{r}$ $=0.52$ ) with eating rate. However due to labeling laws, transfats are disappearing from the food supply so this is likely to be maintained in future versions of the AHEI.

This finding is consistent with numerous studies on eating rate by food type. Numerous studies demonstrate that minimally processed raw foods require increased oral processing time [21]. Further studies link oral sensory exposure (oral processing time) to higher satiation, identifying sensory attributes including the number of times food is chewed and the length of exposure to foods per bite as key factors influencing sensory attributes of food consumption to satiety [29]. High fat and energy dense foods are associated with faster eating rates, as they are easy to chew and consume quickly [29]. These findings suggest that further study between eating rate and diet quality is warranted, and that an eating rate intervention still offers promise as a behavioral intervention that may result in increased diet quality if instruction to reduce consumption of energy dense foods and foods with added sugars is included in the intervention. 
Future studies evaluating the influence of eating behavior on diet quality may consider the strength of social influences on eating, particularly in key age groups. Eating companions may exert substantial influence on eating behavior: studies find that paired individuals mirror consumption behavior [30]. This finding is particularly important for college age populations, where food choices and diet quality may significantly change outside the family meal context. New eating companions are more likely to mirror companion eating behavior when the companions and social context are new [31, 32].

Diet quality has been identified as a key factor in obesity and is independently associated with mortality risk from cancer, CVD, and inflammatory disease [1, 15]. Calorie restricting diets remain limited in their efficacy. Identifying strategies to target within meal eating behavior offers a new avenue for intervention that may facilitate long term change not limited to the intervention period. Results of this study confirm previous research that eating pace intervention is effective [33]. Future research is needed to develop interventions that can affect diet quality through moderating eating behaviors. 
Literature Cited

1. Belin, R.J., et al., Diet quality and the risk of cardiovascular disease: the Women's Health Initiative (WHI). Am J Clin Nutr, 2011. 94(1): p. 49-57.

2. Wolongevicz, D.M., et al., Diet quality and obesity in women: the Framingham Nutrition Studies. Br J Nutr, 2010. 103(8): p. 1223-9.

3. Ford, E.S., et al., Explaining the decrease in U.S. deaths from coronary disease, 1980-2000. N Engl J Med, 2007. 356(23): p. 2388-98.

4. Maclean, P.S., et al., Biology's response to dieting: the impetus for weight regain. Am J Physiol Regul Integr Comp Physiol, 2011. 301(3): p. R581-600.

5. Guenther, P.M., et al., Evaluation of the Healthy Eating Index-2005. Journal of the American Dietetic Association, 2008. 108(11): p. 1854-1864.

6. McCullough, M.L., et al., Adherence to the Dietary Guidelines for Americans and risk of major chronic disease in men. American Journal of Clinical Nutrition, 2000. 72(5): p. 1223-1231.

7. McCullough, M.L., et al., Diet quality and major chronic disease risk in men and women: moving toward improved dietary guidance. Am J Clin Nutr, 2002. 76(6): p. 1261-71.

8. McCullough, M.L., et al., Adherence to the Dietary Guidelines for Americans and risk of major chronic disease in women. American Journal of Clinical Nutrition, 2000. 72(5): p. 1214-1222.

9. Mokdad, A.H., et al., The Continuing Epidemics of Obesity and Diabetes in the United States. JAMA: The Journal of the American Medical Association, 2001. 286(10): p. 1195-1200. 
10. Ogden, C.L., et al., Prevalence of overweight and obesity in the United States, 1999-2004. JAMA, 2006. 295(13): p. 1549-55.

11. Fact sheets from the Surgeon General's Call to Action to Prevent and Decrease Overweight and Obesity. W V Med J, 2002. 98(6): p. 234-43.

12. Hann, C.S., et al., Validation of the Healthy Eating Index with use of plasma biomarkers in a clinical sample of women. American Journal of Clinical Nutrition, 2001. 74(4): p. 479-486.

13. Milner, R.T., Consortium Publishes Its Guidelines for a National Nutrition Policy. Food Technology, 1974. 28(7): p. 20-\&.

14. WELSH, S., C. DAVIS, and A. SHAW, Development of the Food Guide Pyramid. Nutrition Today, 1992. 27(6): p. 12-23.

15. Mursu, J., et al., Diet quality indexes and mortality in postmenopausal women: the Iowa Women's Health Study. Am J Clin Nutr, 2013. 98(2): p. 444-53.

16. Fung, T.T., et al., A prospective study of overall diet quality and risk of type 2 diabetes in women. Diabetes Care, 2007. 30(7): p. 1753-7.

17. Reedy, J., et al., Index-based dietary patterns and risk of colorectal cancer: the NIH-AARP Diet and Health Study. Am J Epidemiol, 2008. 168(1): p. 38-48.

18. Fung, T.T., et al., Diet quality is associated with the risk of estrogen receptornegative breast cancer in postmenopausal women. J Nutr, 2006. 136(2): p. 466-72.

19. Akbaraly, T.N., et al., Alternative Healthy Eating Index and mortality over 18 y of follow-up: results from the Whitehall II cohort. Am J Clin Nutr, 2011. 94(1): p. 247-53. 
20. Otsuka, R., et al., Eating fast leads to obesity: Findings based on selfadministered questionnaires among middle-aged Japanese men and women. Journal of Epidemiology, 2006. 16(3): p. 117-124.

21. Viskaal-van Dongen, M., F.J. Kok, and C. de Graaf, Eating rate of commonly consumed foods promotes food and energy intake. Appetite, 2011. 56(1): p. 25-31.

22. DiMeglio, D.P. and R.D. Mattes, Liquid versus solid carbohydrate: effects on food intake and body weight. Int J Obes Relat Metab Disord, 2000. 24(6): p. 794-800.

23. Blundell, J.E., S. Goodson, and J.C. Halford, Regulation of appetite: role of leptin in signalling systems for drive and satiety. Int J Obes Relat Metab Disord, 2001. 25 Suppl 1: p. S29-34.

24. van Horn, L.V., et al., The Dietary Intervention Study in Children (DISC): dietary assessment methods for 8- to 10-year-olds. J Am Diet Assoc, 1993. 93(12): p. 1396-403.

25. Cohen, J., Statistical Power Analysis and Research Results. American Educational Research Journal, 1973. 10(3): p. 225-230.

26. Fowles, E.R., et al., Stress, depression, social support, and eating habits reduce diet quality in the first trimester in low-income women: a pilot study. J Acad Nutr Diet, 2012. 112(10): p. 1619-25.

27. Kreidler, S.M., et al., : Online Power Computation for Linear Models with and without a Baseline Covariate. J Stat Softw, 2013. 54(10). 
28. Guo, Y., et al., Selecting a sample size for studies with repeated measures. BMC Med Res Methodol, 2013. 13: p. 100.

29. Forde, C.G., et al., Oral processing characteristics of solid savoury meal components, and relationship with food composition, sensory attributes and expected satiation. Appetite, 2013. 60(1): p. 208-19.

30. Hermans, R.C., et al., Mimicry of food intake: the dynamic interplay between eating companions. PLoS One, 2012. 7(2): p. e31027.

31. Birch, L.L. and J.O. Fisher, Development of eating behaviors among children and adolescents. Pediatrics, 1998. 101(3 Pt 2): p. 539-49.

32. Eccles, J.S., The development of children ages 6 to 14. Future Child, 1999. 9(2): p. 30-44.

33. Andrade, A.M., G.W. Greene, and K.J. Melanson, Eating slowly led to decreases in energy intake within meals in healthy women. J Am Diet Assoc, 2008. 108(7): p. 1186-91. 
Table 1. Mean Demographic \& Macronutrient Values by Group at Baseline

\begin{tabular}{|l|c|c|}
\hline \hline Variable & $\begin{array}{c}\text { Control n=10 } \\
\text { mean (SD) }\end{array}$ & $\begin{array}{c}\text { Intervention n=12 } \\
\text { mean (SD) }\end{array}$ \\
\hline Age (years) & $20.4(2.91)$ & $19.1(1.02)$ \\
\hline Weight (pounds) & $183.2(27.2)$ & $188.1(22.7)$ \\
\hline BMI (kg/m ${ }^{2}$ ) & $31.6(2.9)$ & $31.8(2.49)$ \\
\hline AHEI & $38.0(11.0)$ & $41.1(11.3)$ \\
\hline AHEI without alcohol or multivitamin & $35.0(9.0)$ & $36.0(10.3)$ \\
\hline NDSR (calories) & $1588.1(369.7)$ & $1751.0(499.0)$ \\
\hline Fat (grams) & $59.2(19.2)$ & $65.7(28.7)$ \\
\hline Carbohydrate (grams) & $206.7(62.0)$ & $288.7(66.0)$ \\
\hline Protein (grams) & $59.8(13.6)$ & $66.0(15.9)$ \\
\hline Fiber (grams) & $14.6(6.34)$ & $16.1(8.5)$ \\
\hline Sugar Sweetened Beverages (servings) & $0.89(1.0)$ & $1.13(1.6)$ \\
\hline Eating Rate (calories/minute) & $49.3(15.9)$ & $55.0(24.9)$ \\
\hline \hline SD & & \\
\hline
\end{tabular}

SD- standard deviation, $\mathrm{kg} / \mathrm{m}^{2-}$ kilograms divided by meters squared 


\begin{tabular}{|c|c|c|c|c|c|c|c|c|c|}
\hline \multirow{3}{*}{ Variable } & \multirow{3}{*}{ Group } & Pre & Post & \multirow{2}{*}{\multicolumn{3}{|c|}{ Time $\mathrm{x}$ group }} & \multirow{2}{*}{\multicolumn{3}{|c|}{ Time }} \\
\hline & & \multirow{2}{*}{$\begin{array}{c}\text { Mean } \\
( \pm \text { SD })\end{array}$} & \multirow{2}{*}{$\begin{array}{c}\text { Mean } \\
( \pm \text { SD) }\end{array}$} & & & & & & \\
\hline & & & & $\mathrm{F}$ & $\mathrm{p}$ & Eta SQ & $\mathrm{F}$ & $\mathrm{p}$ & Eta SQ \\
\hline \multirow{2}{*}{ AHEI } & $\begin{array}{l}\text { Intervention } \\
(\mathrm{n}=12)\end{array}$ & $\begin{array}{c}41.11 \\
(11.34)\end{array}$ & $\begin{array}{c}40.02 \\
(10.95)\end{array}$ & \multirow{2}{*}{0.3} & \multirow{2}{*}{0.865} & \multirow{2}{*}{0.001} & \multirow{2}{*}{0.112} & \multirow{2}{*}{0.741} & \multirow{2}{*}{0.006} \\
\hline & $\begin{array}{l}\text { Control } \\
(\mathrm{n}=10)\end{array}$ & $\begin{array}{c}37.97 \\
(10.85)\end{array}$ & $\begin{array}{c}35.96 \\
(16.45)\end{array}$ & & & & & & \\
\hline \multirow{2}{*}{$\begin{array}{l}\text { AHEI } \\
\text { Adjusted }\end{array}$} & $\begin{array}{l}\text { Intervention } \\
(\mathrm{n}=12)\end{array}$ & $\begin{array}{c}36.04 \\
(10.31) \\
\end{array}$ & $\begin{array}{c}33.02 \\
(10.40) \\
\end{array}$ & \multirow[b]{2}{*}{0.013} & \multirow[b]{2}{*}{0.909} & \multirow[b]{2}{*}{0.001} & \multirow[b]{2}{*}{0.003} & \multirow[b]{2}{*}{0.957} & \multirow[b]{2}{*}{0.000} \\
\hline & $\begin{array}{l}\text { Control } \\
(\mathrm{n}=10)\end{array}$ & $\begin{array}{l}35.49 \\
(9.29)\end{array}$ & $\begin{array}{l}33.10 \\
(16.7)\end{array}$ & & & & & & \\
\hline \multirow{2}{*}{$\begin{array}{l}\text { Eating } \\
\text { Rate } \\
\text { (kcal/min) }\end{array}$} & $\begin{array}{l}\text { Intervention } \\
(\mathrm{n}=12)\end{array}$ & $\begin{array}{c}54.98 \\
(24.88)\end{array}$ & $\begin{array}{c}35.17 \\
(18.25)\end{array}$ & \multirow{2}{*}{12.97} & \multirow{2}{*}{0.002} & \multirow{2}{*}{0.393} & \multirow{2}{*}{0.340} & \multirow{2}{*}{0.566} & \multirow{2}{*}{0.017} \\
\hline & $\begin{array}{l}\text { Control } \\
(\mathrm{n}=10)\end{array}$ & $\begin{array}{c}48.59 \\
(16.60)\end{array}$ & $\begin{array}{c}50.65 \\
(15.96)\end{array}$ & & & & & & \\
\hline
\end{tabular}




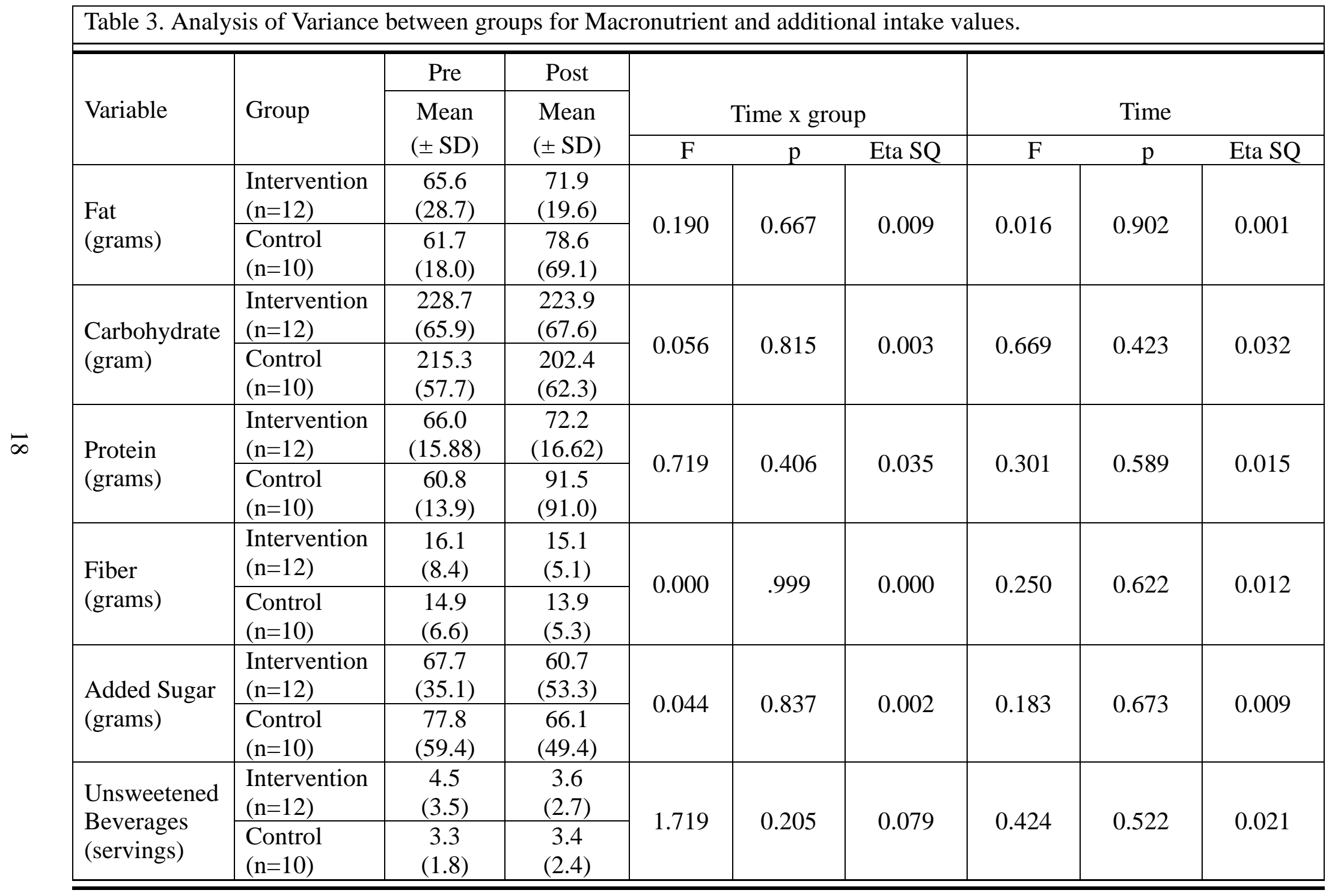


Appendix A: Review of Literature

\section{Introduction}

Nearly two thirds of Americans are overweight or obese (Lloyd-Jones, 2010). Obesity is a primary contributing factor to increases in cardiovascular diseases (CVD), type 2 diabetes and lower life expectancy (Lloyd-Jones, 2010). Children born today may be the first generation to have a lower life expectancy than their parents (LloydJones, 2010). Arterial lesions and atherosclerotic plaque, common risk factors for CVD, have been found in the 18 to 24 year age group (Strong et al., 1999). These trends have resulted in an increased focus on strategies to manage weight and improve health, as in the United States, CVD remains the number one cause of death, killing more women than any other single cause (Lloyd-Jones, 2010; Minino, Heron, Murphy, \& Kochanek, 2007). Reductions in major risk factors, including obesity and poor diet quality, have been demonstrated to decrease deaths from CVD (Ford et al., 2007). Women may be at greater risk of becoming overweight or obese than men; one in three women over the age of twenty is obese (Wolongevicz et al., 2010). Studies attribute the rise in CVD, stroke, diabetes, and osteoarthritis to this increase in obesity, and identify poor diet quality as a primary causal factor (Wolongevicz et al., 2010). Diet quality continues to evolve with greater understanding of nutrient body interactions. Measures of high diet quality can include macronutrient percentages and type of macronutrient including polyunsaturated, monounsaturated, and saturated fats. Other major nutrient components that influence diet quality include fiber, alcohol and 
sodium (Wolongevicz et al., 2010). While research exists to suggest a connection between diet quality and the pace at which food is consumed exists, to date, no behavioral intervention has effectively evaluated the influence of change in eating behaviors on diet quality. The objective of this study is to evaluate relationships between within-meal eating rate and diet quality, and the influence of participation in an eating rate intervention on diet quality.

Obesity

In the United States, being overweight or obese is categorized by Body Mass Index (BMI) of greater than 25 and $30 \mathrm{~kg} / \mathrm{m}^{2}$ respectively [32]. Recent Centers for Disease Control (CDC) publications identify over two thirds of adults in the United States as overweight or obese, by 2015 this number is expected to reach three quarters of the population (Baskin, Ard, Franklin, \& Allison, 2005; Ogden et al., 2006; Paddon-Jones et al., 2008; Wang \& Beydoun, 2007). The CDC also estimates that 17\% of children and adolescents are obese (Ogden, Carroll, Kit, \& Flegal, 2014). As previously noted, numerous factors contribute to obesity, including excessive food intake and poor diet quality.

The health consequences of obesity are substantial; obesity is associated with chronic disease risk including Type II diabetes, coronary artery and cardiovascular disease, stroke, cancer, hypertension, arthritis, reproductive complications, and dyslipidemia (Paddon-Jones et al., 2008; Tanihara et al., 2011; Veldhorst et al., 2008). Obesity is associated with decreased quality of life and diminished life expectancy. Recent studies estimate that obesity at age 40 decreases life expectancy for women by 
3.3 years and for men by 3.1 years (Lloyd-Jones, 2010; D. Lloyd-Jones et al., 2009) . A complementary finding by Adams et al. found that in a study of approximately 500,000 men aged 50 to 71, obese individuals lived shorter lives (Adams et al., 2006). Increases in the degree of obesity also correspond to declines in life expectancy; one study found that for every one unit increase in BMI, the risk of death from cardiovascular complications increases 8\% (Owen et al., 2009). The health consequences of obesity are not limited to purely physical ailments and diminished length of life. Obesity is also associated with increased pain, discomfort, and a higher incidence of depression (Pal \& Ellis, 2010). In sum, obesity is associated with diminished life span characterized by decreased quality of life.

\section{Obesity and College Students}

Adolescence and early adulthood are identified as critical times in forming lifelong eating habits. As students transition to independent living, they leave the social context of their families and encounter new social influences on food consumption. In fact, removal from the family eating context combined with stress and increased alcohol consumption are in identified as factors contributing to weight gain in college populations (Racette, Deusinger, Strube, Highstein, \& Deusinger, 2005, 2008). Between the ages of 18 and 29, dramatic increases in the rate of obesity are observed, the greatest increase in any age group (Lloyd-Richardson, Bailey, Fava, \& Wing, 2009). Current studies approximate that $35 \%$ of college students are overweight (T. T. Huang et al., 2003). Studies of student weight gain characterize the first several years of college as important in forming eating habits that may persist in the long term 
(Cluskey \& Grobe, 2009; Edmonds et al., 2008; Hetherington, Anderson, Norton, \& Newson, 2006; Holm-Denoma, Joiner, Vohs, \& Heatherton, 2008). Unfortunately, many of these eating habits are centered on the consumption of energy dense foods and poor diet, facilitated by dining halls offering limitless portions, an emphasis on the consumption of high fat foods and snacks, and the consumption of junk food (Levitsky, Halbmaier, \& Mrdjenovic, 2004).

In a study of students over a two year period, participant weight was observed to increase an average of 7.7 pounds $(p<0.05)$ in the first year of the study, with the number of total participants categorized as overweight increasing substantially: this finding is supported by other examinations (Hetherington et al., 2006; Mokdad et al., 2001; Ogden et al., 2006). Seventy percent of overweight adolescents will remain overweight as adults ("Fact sheets from the Surgeon General's Call to Action to Prevent and Decrease Overweight and Obesity," 2002). In a study of female college students over their freshman year, Lloyd-Richardson found that obesity rates increased from $14.7 \%$ to $17.8 \%$ (Lloyd-Richardson et al., 2009). In fact, many college women fail to meet USDA dietary guidelines, and first year college students have been identified in recent studies as at risk of developing chronic diseases due to unhealthy dietary habits (Irazusta et al., 2007; Racette et al., 2005; Sharma et al., 2008). This may be due in part to retention of eating behaviors established during adolescence and the resulting influence on nutrient intake (Dwyer et al., 2001). Some of these behaviors can include binge eating, excessive calorie consumption, and the consumption of between meal snacks (Dwyer et al., 2001). Two elements of eating 
behavior are discussed in relation to this study: social and contextual influences on eating and eating rate or pace.

\section{Social Influences on Eating}

The motivation for eating is prompted by appetite, however habit, stress, boredom, and the social environment also contribute to the quantity of food an individual consumes (de Graaf, Blom, Smeets, Stafleu, \& Hendriks, 2004; Melanson, 2004). Several explanations are offered for this phenomenon. The logic examining social influences on food consumption identifies factors such as environment, timing, and social context of eating as important factors influencing food consumption (Stroebele \& De Castro, 2004). A series of studies argue that the number of eaters in a given environment influences the period of time individuals spend eating, with increases in the number of total participants resulting in increase of both the meal duration and total caloric intake (Hetherington et al., 2006). In a college setting where individuals may be eating in large social groups, for example in dining halls, this has real implications for the quantity of food consumed. Other studies identify explanations that rely on theories of impression management or behavioral modeling; each of these explanations rests on the notion that eating companions exert powerful influences on eating behavior. Impression management identifies food consumption quantity as influenced by the choices of peer individuals within an environment (Pliner, Bell, Hirsch, \& Kinchla, 2006; Pliner \& Mann, 2004; Salvy, Jarrin, Paluch, Irfan, \& Pliner, 2007; Vartanian, Herman, \& Polivy, 2007). Modeling explanations focus on mirroring types of behavior that individuals unconsciously adopt when eating 
in a companion setting (Hermans et al., 2012). A study of 70 young adult female eating pairs found that eating companions exerted substantial influence on eating behavior: when a companion ate more, so did the paired individual, when the companion ate less, paired individual food intake also decreased (Hermans et al., 2012). Each of these approaches suggests that college is an important period of time for shaping eating behaviors. Students are in a new environment outside the structure and context of family meals. Companions are often new and inconsistent during meal time, and the social and behavioral setting has significantly changed in terms of meals.

A complimentary and interesting approach to social influences on eating examines the identification of individuals by their style of eating. This approach considers different types of motivation, internal and external in the regulation of eating behaviors suggesting that some individuals are very autonomous in their eating behaviors while others rely and are influenced by external cues and social conditions (Leong, Madden, Gray, \& Horwath, 2012). A New Zealand study of 2500 women between the ages of 40 and 50 found that demonstrating self-determined, or autonomous, eating behavior was associated with higher diet quality (measured by the New Zealand National Nutrition Survey) and lower BMI (Leong et al., 2012). In considering the influence of environment on eating behaviors and habits, college demonstrates an important opportunity for intervention and a window for decreasing increased weight gain. The previous summarized research suggests that the changed social environment and context represents both a window for the formation of unhealthy eating habits and an opportunity for eating behavioral interventions that can yield more positive outcomes in energy balance. 


\section{Eating Rate}

Eating rate measured in the lab is defined as the quantity of food consumed every minute over the duration of a single meal (Melanson, 2004). Eating quickly and binge eating are associated with higher energy intake and increases in being overweight or obese (Ebbeling et al., 2007). Slowing eating pace has been identified as a factor in a number of studies that may assist in managing weight because slowing the consumption of food consumption has been associated with increases in satiety (Ferster, Nurnberger, \& Levitt, 1996). Satiety is increased through two distinct mechanisms: the physical volume of food in the stomach and metabolic factors including internal biomarkers including peptides and hormones that function to signal fullness to the brain (de Graaf et al., 2004; Melanson, 2004). Martin et al. suggest that slower eating pace allows satiety cues to activate with lower calorie consumption and functions to allow individuals to experience more enjoyment with the consumption of fewer calories (Martin et al., 2007). In a controlled eating rate study of six obese and six non-obese males, regardless of weight, all consumed more food at the faster eating rate and reported that the food tasted better at the conclusion of the meal when it was consumed at a more rapid rate (Kaplan, 1980). A similar study that manipulated eating rate in thirty healthy women found satiation upon meal completion to be greater and intake lower when the participants were asked to eat at the slower pace (Andrade, Greene, \& Melanson, 2008). Comparisons of palatability and food consumption found that a more seasoned or palatable meal increased eating rate and food consumption (Yeomans, Gray, Mitchell, \& True, 1997). In studies of self-reported 
eating rate, the findings are consistent. For example, Otuska et al. found that in 20 year old women $(\mathrm{n}=3465)$, fast eating rate is associated with obesity (Otsuka et al., 2006). Similar results were found in middle aged New Zealand women. These findings support the contention that both long term habits and within meal behaviors influence the quantity and quality of food consumed. The rationale that slower eating rate is associated with higher diet quality is supported by several studies. A study examining the eating rate of 50 common foods demonstrated that energy dense processed foods were associated with faster eating rates and unprocessed raw high fiber foods were associated with slower eating rates $(\mathrm{p}<0.001)$ (Viskaal-van Dongen, Kok, \& de Graaf, 2011). In an evaluation of 50 commonly consumed foods, the fastest food consumed was consumed 160 times faster than the slowest food (Viskaalvan Dongen, Kok, \& de Graaf, 2011). Sensory cues of satiation are inhibited with faster eating rates including those induced by chewing and taste; responses to changes in the energy density of consumed foods are also inhibited by eating quickly (DiMeglio \& Mattes, 2000). Eating quickly may inhibit the satiety cascade, delaying responses to change in physical volume in the stomach and in metabolic pathways (Blundell, Goodson, \& Halford, 2001).

Some studies of eating rate caution the influence of intervention on instituting behavioral change. A recent study of 35 normal weight and 35 overweight and obese men and women found that slower eating rate reduced energy intake in normal weight individuals but did not reduce energy intake in overweight and obese individuals (Shah et al., 2014). This may be a consequence of learned eating behaviors and the strength of dietary habits discussed above. 


\section{Eating rate and Diet Quality}

Several studies suggest an association between slower eating rate and higher diet quality. A study of Japanese dietetic students $(n=3465)$ demonstrated a significant relationship between self-reported eating rate, BMI, total energy intake, and carbohydrate intake (Sasaki, Katagiri, Tsuji, Shimoda, \& Amano, 2003). Using self-administered validated one month diet history questionnaires, researchers found significant differences between very slow and very fast eaters in intakes of total energy, carbohydrate $(\mathrm{p}<0.01)$, and fiber $(\mathrm{p}<0.001)$, as well as BMI $(\mathrm{p}<0.01)$; where fast eaters had higher total energy intake and BMI, consumed more carbohydrates, and less fiber) (Sasaki et al., 2003). This suggests that slower eaters may have higher diet quality and lower energy intake. A cross sectional study of 2704 men and 761 women found that, after controlling for age, energy intake, and lifestyle, faster eating rates were associated with increased Homeostasis Model of Assessment - Insulin Resistance (HOMA-IR) $\mathrm{p}<0.01$ for women (Otsuka et al., 2006). Further, a study of 3737 male and 1005 female Japanese civil servants found eating rate in women had a positive influence on current BMI (very slow -1.06 lower BMI compared to very fast 1.34 higher BMI) and BMI change from age 20 to current age (very slow -0.71 compared to very fast 1.14) controlling for lifestyle and energy intake (Otsuka et al., 2006). Laboratory-assessed faster eating rates have also been associated with insulin resistance and higher percentage of body fat in Pima Indians (Rising, Larson, \& Ravussin, 1992). 


\section{Diet Quality}

Numerous measures exist to evaluate diet quality; most of these indices intend to provide direction for appropriate and healthy food intake to individuals (Fung, McCullough, van Dam, \& Hu, 2007; Fung et al., 2005) . Fung et al. find that most indices of diet quality, including HEI, the AHEI, Diet Quality Index (DQI), Recommended Food Score (RFS), and alternate Mediterranean Diet Index (aMDI) are highly correlated when evaluating individual food scores (Fung et al., 2005). Measures of high diet quality can include macronutrient percentages and type of macronutrient including polyunsaturated, monounsaturated, and saturated fats. Other major nutrient components that influence diet quality include, but are not limited to fiber, alcohol and sodium (Wolongevicz et al., 2010). There is no established consensus on the components or measurement of diet quality currently in the literature.

Early studies on the relationship between diet quality and disease primarily focused on single nutrient intake, limiting inferences (Reiser, 1978). Consensus on the importance of overall diet quality resulted in the creation of the National Nutrition Policy for Americans, the USDA Food Pyramid, and ultimately the healthy eating index HEI (Hann, Rock, King, \& Drewnowski, 2001; Milner, 1974; WELSH, DAVIS, \& SHAW, 1992). Support for these contentions were demonstrated in the $30 \%$ lower risk of death in a study of more than 40,000 women based on diet quality estimated by Recommended Food Score (Kant, Schatzkin, Graubard, \& Schairer, 2000). The Framingham Offspring and Spouse Study followed 1,265 women, ages 25 to 71 with no CVD risk over a 16 year period and found a substantial influence of diet quality on 
the risk of becoming overweight or obese (Wolongevicz et al., 2010). Further, a twelve year study of 67,271 US female nurses, surveyed healthy eating by HEI and chronic disease, finding a 28\% risk reduction in CVD for women in the highest diet quality quintile compared to the lowest using the HEI (McCullough et al., 2002). Studies focused on overall diet quality, with an emphasis on food patterns rather than individual nutrient intake such as the Iowa Women's Study of 29,334 postmenopausal women, found that AHEI and a priori diet quality scores predicted both total mortality and CVD, cancer and inflammatory-related mortality (Mursu, Steffen, Meyer, Duprez, \& Jacobs, 2013). Additional recent studies have found an association between better diet quality (HEI) and decreased mortality from cancer and inflammatory disease in post-menopausal women (Mursu et al., 2013).

Increasingly research has supported the use of the AHEI. Fung et al. found that after controlling for the influence of age, alcohol consumption, activity level, energy intake, smoking, and BMI, only higher AHEI and the aMED scores were associated with lower markers for inflammation and endothelial dysfunction, and associated with decreased risk of CVD and diabetes (Fung et al., 2005). Other studies support a substantial influence of AHEI scores on health. A comparison of the top third of AHEI scores to the bottom third of AHEI scores found a 25\% decrease in mortality of any cause and a 40\% decrease in CVD (Akbaraly et al., 2011).

In part, the AHEI is a powerful measure of diet quality because every sub component is associated with benefits to long term health. The AHEI comprised of the following sub components: vegetables, fruits, nuts \& soy, ratio of white to red meat, fiber, trans fat, ratio of polyunsaturated to saturated fat, multivitamin use 
and alcohol consumption. Consumption of vegetables, ideally five servings per day, has been associated with lower risk of chronic disease (Appel et al., 1997; McCullough, Feskanich, Rimm, et al., 2000; McCullough et al., 2002; McCullough, Feskanich, Stampfer, et al., 2000; Steinmetz \& Potter, 1991). Similarly, fruit consumption has been associated with lower risk of CVD, with ideal consumption identified as four servings per day (McCullough, Feskanich, Rimm, et al., 2000; McCullough et al., 2002; McCullough, Feskanich, Stampfer, et al., 2000). The composition of fats in the diet is also important overall health. High consumption of transfats has been associated with increases in the risk of coronary heart disease, while the consumption of polyunsaturated fats are associated with lower risks of coronary heart disease (Willett et al., 1993). Ideal consumption of nut and soy has been identified as one serving per day and is also associated with lower risk of CVD (Hu et al., 1998; McCullough, Feskanich, Rimm, et al., 2000; McCullough et al., 2002; McCullough, Feskanich, Stampfer, et al., 2000). Fiber consumption is associated with lower risks of coronary heart disease and lower risk of stroke (Mursu et al., 2013). Red meat consumption is associated with increased health risks including colorectal cancer and CVD, while consumption of lean protein is associated with lower risks of CVD ("Fact sheets from the Surgeon General's Call to Action to Prevent and Decrease Overweight and Obesity," 2002; Fung \& Brown, 2013).

Multivitamins are somewhat mixed in terms of evidence on the benefits for health outcomes. Results of two large cohorts examined the influence of multivitamin intake on the prevention of cancer and CVD, finding very borderline benefits for men in cancer prevention (unadjusted relative risk of 0.93 [95\% CI, 0.87 to 0.99 ]) and no 
effect of multivitamin intake on CVD or cancer in women (Fortmann, Burda, Senger, Lin, \& Whitlock, 2013). Futhermore, beta carotene was associated with increased risk of lung cancer in smokers (Fortmann et al., 2013). Lamas et al. examine the influence of multivitamin intake in 1708 patients aged 50 who had experienced myocardial infarction in the prevention of additional cardiac events; the study yielded no significant influence however inferences were limited due to non-adherence (Lamas et al., 2013). Alcohol intake is similarly mixed in studies of influences on health. Moderate alcohol intake is associated in some studies with decreased risk of heart disease while high alcohol intake is associated with increases in liver and kidney disease, diabetes, and heart disease (McCullough, Feskanich, Rimm, et al., 2000; McCullough et al., 2002; McCullough, Feskanich, Stampfer, et al., 2000).

Other sources of calories also influence health. For example, the consumption of sugar sweetened beverages is associated with increased LDL levels and chronic disease risk (C. Huang, Huang, Tian, Yang, \& Gu, 2014). A meta-analysis of four studies including 173,753 particpants by Huang et al. found a pooled risk ratio of 1.17 (1.07-1.28) of CHD for the population consuming the largest quantity of sugar sweetened beverages; in practical terms this translates into a 16\% increase in CHD for every increase daily serving of sugar sweetened beverages (C. Huang et al., 2014). Increased focus on added sugar has often concentrated on children and adolescents. However, added sugars are associated with increased health risks including Type II diabetes and colorectal cancer in adults (Fung \& Brown, 2013). In a study of NHANES data from 2003 to 2006, Huth et al. found that as added sugar and saturated fat intake increased in individuals the ratio of these items to healthy foods also 
increased, with a consequence of greatly diminishing overall diet quality(Huth, Fulgoni, Keast, Park, \& Auestad, 2013). While the study cautioned that no single food source comprised more than $7.2 \%$ of overall food intake during the study period, researchers also noted that $83 \%$ of foods containing added sugar and saturated fat had no nutritional value resulting in substantially decreased macronutrient consumption and much lower diet quality (Huth et al., 2013).

\section{Conclusion}

This study took an initial step in identifying whether within-meal eating behaviors, specifically eating rate, influence diet quality in overweight and obese females. Traditionally, behavior change interventions have focused on the "what" and "how much" aspects of a diet. No current interventions have focused solely on the act of eating, despite initial research that suggests that pace at which food is consumed during a meal may influence the quantity and type of food consumed. Limitations of the study include sample size which was powered on eating rate, study population, and duration of the study. No association was demonstrated between eating rate and diet quality. However, diet quality is associated with significant improvements in chronic disease risk, mortality, obesity, and quality of life. Thus, the ability to influence diet quality through behavioral interventions merits consideration and further study. 


\section{Appendix B}

\section{Test Meal Day Instructions}

Please follow the instructions below on the days of your test meal and bring this form with you to the lab.

On the morning of your visit:

- Consume the following standardized breakfast 4 hours before your lab visit:

o 8 oz orange juice

o 8 oz $1 \%$ or $2 \%$ milk (please circle the one you choose)

o 1 cup of ready-to-eat cereal (except granola or Grape-Nuts)

please specify the kind of cereal consumed

- Do not have any caffeine (8 oz of decaf coffee or tea is okay)

- Do not consume any food or beverages other than water or the standard breakfast prior to the test lunch

- Record the start and stop time of your standardized breakfast

START a.m.
STOP a.m.

- Avoid any strenuous physical activity and any activity that is not normally in your daily routine 
Appendix C

Additional Tables

Table 4: Study Timeline

\begin{tabular}{|l|}
\hline 2011 \\
\hline January \\
\hline IRB approval \\
\hline Recruitment \\
\hline February \\
\hline Recruitment \\
\hline Baseline testing \\
\hline Intervention begins \\
\hline March \\
\hline Baseline testing \\
\hline Intervention begins \\
\hline April \\
\hline Baseline testing \\
\hline Intervention begins/ends \\
\hline Post testing \\
\hline May \\
\hline Data entry \\
\hline Post testing \\
\hline
\end{tabular}


Table 5: Intervention Overview

\begin{tabular}{|l|l|}
\hline \multicolumn{2}{|l|}{ Eating Pace Instruction Classes Intervention } \\
\hline Week 1 & Introduction to the importance of within-meal behaviors \\
\hline Week 2 & Within-meal awareness (enjoyment, hunger and satiety) \\
\hline Week 3 & Physiological cues (true hunger and satiation; meal termination) \\
\hline Week 4 & Non-physiological cues of meal initiation and termination \\
\hline Week 5 & Review and strategies for maintenance \\
\hline
\end{tabular}




\begin{tabular}{|l|c|c|c|}
\hline Table 6: Intake Between Groups Post Intervention (n=22) \\
\hline & $\begin{array}{l}\text { Mean } \\
\text { Difference }\end{array}$ & $\begin{array}{l}\text { 95\% Confidence } \\
\text { Interval }\end{array}$ & $\begin{array}{l}\text { Probability } \\
\text { Value }\end{array}$ \\
\hline AHEI & 2.01 & -8.12 to 10.84 & 0.53 \\
\hline Change in AHEI & 0.95 & -10.26 to 12.11 & 0.86 \\
\hline $\begin{array}{l}\text { Change in Eating Rate } \\
\text { (kcal) }\end{array}$ & -21.87 & -34.54 to -9.20 & $0.002 *$ \\
\hline Change in NDSR (kcal) & -109.54 & -990.83 to 772.76 & 0.78 \\
\hline Fiber (g) & 1.13 & -3.73 to 5.98 & 0.63 \\
\hline Fat (g) & -6.67 & -50.07 to 36.71 & 0.75 \\
\hline Carbohydrate (g) & 21.50 & -36.85 to 79.85 & 0.45 \\
\hline Protein (g) & -19.37 & -75.04 to 36.29 & 0.48 \\
\hline Added sugar (g) & -5.39 & -51.45 to 40.67 & 0.81 \\
\hline Sugar Sweetened (bev) & -3.39 & -3.72 to 5.97 & 0.63 \\
\hline Vegetables (c) & 1.21 & -0.68 to 3.11 & 0.19 \\
\hline Fruit (c) & -4.28 & -3.42 to 2.56 & 0.77 \\
\hline Nut \& Soy (c) & -2.26 & -6.06 to 1.53 & 0.22 \\
\hline White to red meat (c) & 1.46 & -2.42 to 2.98 & 0.44 \\
\hline Cereal (c) & 1.39 & -2.84 to 2.97 & 0.67 \\
\hline Polyunsaturated fat (c) & -3.60 & -3.34 to 1.61 & 0.48 \\
\hline Trans fat (c) & 0.74 & -0.82 to 2.27 & 0.34 \\
\hline $\begin{array}{l}\text { bev- beverages , kcal-calories, g-grams, c-AHEI component; *p }<0.05 ; \\
\text { independent samples t-test }\end{array}$ & \multicolumn{4}{|l}{} \\
\hline
\end{tabular}




\begin{tabular}{|c|c|c|}
\hline \multicolumn{3}{|c|}{$\begin{array}{l}\text { Table 7: One way ANOVA between intervention and control groups } \\
\text { post intervention }\end{array}$} \\
\hline & F Statistic & Probability value \\
\hline AHEI & 0.12 & 0.73 \\
\hline Eating rate & 4.39 & $0.049 *$ \\
\hline Fat & 0.01 & 0.75 \\
\hline Carbohydrate & 0.59 & 0.45 \\
\hline Protein & 0.52 & 0.47 \\
\hline Fiber & 0.23 & 0.63 \\
\hline Added Sugar & 0.05 & 0.81 \\
\hline Vegetables & 1.78 & 0.19 \\
\hline Fruit & 0.89 & 0.76 \\
\hline Nut \& Soy & 1.54 & 0.23 \\
\hline White to red meat & 0.62 & 0.44 \\
\hline Cereal & 0.002 & 0.96 \\
\hline Polyunsaturated & 0.53 & 0.48 \\
\hline Transfats & 0.94 & 0.34 \\
\hline Multivitamin & 6.49 & 0.19 \\
\hline Alcohol & 0.004 & 0.98 \\
\hline
\end{tabular}


Appendix D

Bibliography

(2002). "Fact sheets from the Surgeon General's Call to Action to Prevent and Decrease Overweight and Obesity." W V Med J 98(6): 234-243.

Adams, K. F., A. Schatzkin, T. B. Harris, V. Kipnis, T. Mouw, R. Ballard-Barbash, A. Hollenbeck and M. F. Leitzmann (2006). "Overweight, obesity, and mortality in a large prospective cohort of persons 50 to 71 years old." N Engl J Med 355(8): 763778.

Akbaraly, T. N., J. E. Ferrie, C. Berr, E. J. Brunner, J. Head, M. G. Marmot, A. SinghManoux, K. Ritchie, M. J. Shipley and M. Kivimaki (2011). "Alternative Healthy Eating Index and mortality over $18 \mathrm{y}$ of follow-up: results from the Whitehall II cohort." Am J Clin Nutr 94(1): 247-253.

Andrade, A. M., G. W. Greene and K. J. Melanson (2008). "Eating slowly led to decreases in energy intake within meals in healthy women." Journal of the American Dietetic Association 108(7): 1186-1191.

Andrade, A. M., G. W. Greene and K. J. Melanson (2008). "Eating slowly led to decreases in energy intake within meals in healthy women." J Am Diet Assoc 108(7): 1186-1191.

Appel, L. J., T. J. Moore, E. Obarzanek, W. M. Vollmer, L. P. Svetkey, F. M. Sacks, G. A. Bray, T. M. Vogt, J. A. Cutler, M. M. Windhauser, P. H. Lin and N. Karanja (1997). "A clinical trial of the effects of dietary patterns on blood pressure. DASH Collaborative Research Group." N Engl J Med 336(16): 1117-1124.

Baskin, M. L., J. Ard, F. Franklin and D. B. Allison (2005). "Prevalence of obesity in the United States." Obes Rev 6(1): 5-7.

Belin, R. J., P. Greenland, M. Allison, L. Martin, J. M. Shikany, J. Larson, L. Tinker, B. V. Howard, D. Lloyd-Jones and L. Van Horn (2011). "Diet quality and the risk of cardiovascular disease: the Women's Health Initiative (WHI)." Am J Clin Nutr 94(1): 49-57.

Birch, L. L. and J. O. Fisher (1998). "Development of eating behaviors among children and adolescents." Pediatrics 101(3 Pt 2): 539-549. 
Blundell, J. E., S. Goodson and J. C. Halford (2001). "Regulation of appetite: role of leptin in signalling systems for drive and satiety." Int J Obes Relat Metab Disord 25

Suppl 1: S29-34.

Cluskey, M. and D. Grobe (2009). "College weight gain and behavior transitions: male and female differences." J Am Diet Assoc 109(2): 325-329.

Cohen, J. (1973). "Statistical Power Analysis and Research Results." American Educational Research Journal 10(3): 225-230.

de Graaf, C., W. A. Blom, P. A. Smeets, A. Stafleu and H. F. Hendriks (2004). "Biomarkers of satiation and satiety." Am J Clin Nutr 79(6): 946-961.

DiMeglio, D. P. and R. D. Mattes (2000). "Liquid versus solid carbohydrate: effects on food intake and body weight." Int J Obes Relat Metab Disord 24(6): 794-800.

Dwyer, J. T., M. Evans, E. J. Stone, H. A. Feldman, L. Lytle, D. Hoelscher, C. Johnson, M. Zive, M. H. Yang and C. C. R. Grp (2001). "Adolescents' eating patterns influence their nutrient intakes." Journal of the American Dietetic Association 101(7): 798-802.

Ebbeling, C. B., E. Garcia-Lago, M. M. Leidig, L. G. Seger-Shippee, H. A. Feldman and D. S. Ludwig (2007). "Altering portion sizes and eating rate to attenuate gorging during a fast food meal: effects on energy intake." Pediatrics 119(5): 869-875.

Eccles, J. S. (1999). "The development of children ages 6 to 14." Future Child 9(2): 30-44.

Edmonds, M. J., K. J. Ferreira, E. A. Nikiforuk, A. K. Finnie, S. H. Leavey, A. M. Duncan and J. A. Randall Simpson (2008). "Body weight and percent body fat increase during the transition from high school to university in females." $\mathrm{J}$ Am Diet Assoc 108(6): 1033-1037.

Ferster, C. B., J. I. Nurnberger and E. B. Levitt (1996). "The control of eating. 1962." Obes Res 4(4): 401-410.

Ford, E. S., U. A. Ajani, J. B. Croft, J. A. Critchley, D. R. Labarthe, T. E. Kottke, W. H. Giles and S. Capewell (2007). "Explaining the decrease in U.S. deaths from coronary disease, 1980-2000." N Engl J Med 356(23): 2388-2398.

Forde, C. G., N. van Kuijk, T. Thaler, C. de Graaf and N. Martin (2013). "Oral processing characteristics of solid savoury meal components, and relationship with food composition, sensory attributes and expected satiation." Appetite 60(1): 208-219.

Fortmann, S. P., B. U. Burda, C. A. Senger, J. S. Lin and E. P. Whitlock (2013).

"Vitamin and mineral supplements in the primary prevention of cardiovascular disease 
and cancer: An updated systematic evidence review for the U.S. Preventive Services Task Force." Ann Intern Med 159(12): 824-834.

Fung, T. T. and L. S. Brown (2013). "Dietary Patterns and the Risk of Colorectal Cancer." Curr Nutr Rep 2(1): 48-55.

Fung, T. T., F. B. Hu, M. L. McCullough, P. K. Newby, W. C. Willett and M. D. Holmes (2006). "Diet quality is associated with the risk of estrogen receptor-negative breast cancer in postmenopausal women." J Nutr 136(2): 466-472.

Fung, T. T., M. McCullough, R. M. van Dam and F. B. Hu (2007). "A prospective study of overall diet quality and risk of type 2 diabetes in women." Diabetes Care 30(7): 1753-1757.

Fung, T. T., M. L. McCullough, P. K. Newby, J. E. Manson, J. B. Meigs, N. Rifai, W. C. Willett and F. B. Hu (2005). "Diet-quality scores and plasma concentrations of markers of inflammation and endothelial dysfunction." Am J Clin Nutr 82(1): 163173.

Guenther, P. M., J. Reedy, S. M. Krebs-Smith and B. B. Reeve (2008). "Evaluation of the Healthy Eating Index-2005." Journal of the American Dietetic Association 108(11): 1854-1864.

Hann, C. S., C. L. Rock, I. D. King and A. Drewnowski (2001). "Validation of the Healthy Eating Index with use of plasma biomarkers in a clinical sample of women." American Journal of Clinical Nutrition 74(4): 479-486.

Hermans, R. C., A. Lichtwarck-Aschoff, K. E. Bevelander, C. P. Herman, J. K. Larsen and R. C. Engels (2012). "Mimicry of food intake: the dynamic interplay between eating companions." PLoS One 7(2): e31027.

Hetherington, M. M., A. S. Anderson, G. N. Norton and L. Newson (2006). "Situational effects on meal intake: A comparison of eating alone and eating with others." Physiol Behav 88(4-5): 498-505.

Holm-Denoma, J. M., T. E. Joiner, K. D. Vohs and T. F. Heatherton (2008). "The "freshman fifteen" (the "freshman five" actually): predictors and possible explanations." Health Psychol 27(1 Suppl): S3-9.

Hu, F. B., M. J. Stampfer, J. E. Manson, E. B. Rimm, G. A. Colditz, B. A. Rosner, F. E. Speizer, C. H. Hennekens and W. C. Willett (1998). "Frequent nut consumption and risk of coronary heart disease in women: prospective cohort study." Bmj 317(7169): 1341-1345. 
Huang, C., J. Huang, Y. Tian, X. Yang and D. Gu (2014). "Sugar sweetened beverages consumption and risk of coronary heart disease: A meta-analysis of prospective studies." Atherosclerosis 234(1): 11-16.

Huang, T. T., K. J. Harris, R. E. Lee, N. Nazir, W. Born and H. Kaur (2003). "Assessing overweight, obesity, diet, and physical activity in college students." $\mathrm{J}$ Am Coll Health 52(2): 83-86.

Huth, P. J., V. L. Fulgoni, 3rd, D. R. Keast, K. Park and N. Auestad (2013). "Major food sources of calories, added sugars, and saturated fat and their contribution to essential nutrient intakes in the U.S. diet: data from the national health and nutrition examination survey (2003--2006)." Nutr J 12(1): 116.

Irazusta, A., I. Hoyos, J. Irazusta, F. Ruiz, E. Diaz and J. Gil (2007). "Increased cardiovascular risk associated with poor nutritional habits in first-year university students." Nutrition Research 27(7): 387-394.

Kant, A. K., A. Schatzkin, B. I. Graubard and C. Schairer (2000). "A prospective study of diet quality and mortality in women." JAMA 283(16): 2109-2115.

Kaplan, D. L. (1980). "Eating style of obese and nonobese males." Psychosom Med 42(6): 529-538.

Kreidler, S. M., K. E. Muller, G. K. Grunwald, B. M. Ringham, Z. T. CokerDukowitz, U. R. Sakhadeo, A. E. Baron and D. H. Glueck (2013). ": Online Power Computation for Linear Models with and without a Baseline Covariate." J Stat Softw 54(10).

Lamas, G. A., R. Boineau, C. Goertz, D. B. Mark, Y. Rosenberg, M. Stylianou, T. Rozema, R. L. Nahin, L. Lindblad, E. F. Lewis, J. Drisko and K. L. Lee (2013). "Oral High-Dose Multivitamins and Minerals After Myocardial InfarctionA Randomized Trial." Annals of Internal Medicine 159(12): 797-805.

Leong, S. L., C. Madden, A. Gray and C. Horwath (2012). "Self-determined, autonomous regulation of eating behavior is related to lower body mass index in a nationwide survey of middle-aged women." J Acad Nutr Diet 112(9): 1337-1346.

Levitsky, D. A., C. A. Halbmaier and G. Mrdjenovic (2004). "The freshman weight gain: a model for the study of the epidemic of obesity." Int J Obes Relat Metab Disord 28(11): 1435-1442.

Lloyd-Jones (2010). "Heart Disease and Stroke Statistics-2010 Update: A Report From the American Heart Association (vol 121, pg e46, 2010)." Circulation 121(12): E260-E260. 
Lloyd-Jones, D., R. Adams, M. Carnethon, G. De Simone, T. B. Ferguson, K. Flegal, E. Ford, K. Furie, A. Go, K. Greenlund, N. Haase, S. Hailpern, M. Ho, V. Howard, B. Kissela, S. Kittner, D. Lackland, L. Lisabeth, A. Marelli, M. McDermott, J. Meigs, D. Mozaffarian, G. Nichol, C. O'Donnell, V. Roger, W. Rosamond, R. Sacco, P. Sorlie, R. Stafford, J. Steinberger, T. Thom, S. Wasserthiel-Smoller, N. Wong, J. WylieRosett and Y. Hong (2009). "Heart disease and stroke statistics--2009 update: a report from the American Heart Association Statistics Committee and Stroke Statistics Subcommittee." Circulation 119(3): 480-486.

Lloyd-Richardson, E. E., S. Bailey, J. L. Fava and R. Wing (2009). "A prospective study of weight gain during the college freshman and sophomore years." Prev Med 48(3): 256-261.

Maclean, P. S., A. Bergouignan, M. A. Cornier and M. R. Jackman (2011). "Biology's response to dieting: the impetus for weight regain." Am J Physiol Regul Integr Comp Physiol 301(3): R581-600.

Martin, C. K., S. D. Anton, H. Walden, C. Arnett, F. L. Greenway and D. A. Williamson (2007). "Slower eating rate reduces the food intake of men, but not women: implications for behavioral weight control." Behav Res Ther 45(10): 23492359 .

McCullough, M. L., D. Feskanich, E. B. Rimm, E. L. Giovannucci, A. Ascherio, J. N. Variyam, D. Spiegelman, M. J. Stampfer and W. C. Willett (2000). "Adherence to the Dietary Guidelines for Americans and risk of major chronic disease in men." American Journal of Clinical Nutrition 72(5): 1223-1231.

McCullough, M. L., D. Feskanich, M. J. Stampfer, E. L. Giovannucci, E. B. Rimm, F. B. Hu, D. Spiegelman, D. J. Hunter, G. A. Colditz and W. C. Willett (2002). "Diet quality and major chronic disease risk in men and women: moving toward improved dietary guidance." Am J Clin Nutr 76(6): 1261-1271.

McCullough, M. L., D. Feskanich, M. J. Stampfer, B. A. Rosner, F. B. Hu, D. J. Hunter, J. N. Variyam, G. A. Colditz and W. C. Willett (2000). "Adherence to the Dietary Guidelines for Americans and risk of major chronic disease in women." American Journal of Clinical Nutrition 72(5): 1214-1222.

Melanson, K. J. (2004). "Food Intake Regulation in Body Weight Management: A Primer." Nutrition Today 39(5): 203-213.

Milner, R. T. (1974). "Consortium Publishes Its Guidelines for a National Nutrition Policy." Food Technology 28(7): 20-\&.

Minino, A. M., M. P. Heron, S. L. Murphy and K. D. Kochanek (2007). "Deaths: final data for 2004." Natl Vital Stat Rep 55(19): 1-119. 
Mokdad, A. H., B. A. Bowman, E. S. Ford, F. Vinicor, J. S. Marks and J. P. Koplan (2001). "The Continuing Epidemics of Obesity and Diabetes in the United States." JAMA: The Journal of the American Medical Association 286(10): 11951200 .

Mursu, J., L. M. Steffen, K. A. Meyer, D. Duprez and D. R. Jacobs, Jr. (2013). "Diet quality indexes and mortality in postmenopausal women: the Iowa Women's Health Study." Am J Clin Nutr 98(2): 444-453.

Ogden, C. L., M. D. Carroll, L. R. Curtin, M. A. McDowell, C. J. Tabak and K. M. Flegal (2006). "Prevalence of overweight and obesity in the United States, 19992004." JAMA 295(13): 1549-1555.

Ogden, C. L., M. D. Carroll, B. K. Kit and K. M. Flegal (2014). "PRevalence of childhood and adult obesity in the united states, 2011-2012." JAMA 311(8): 806-814.

Otsuka, R., K. Tamakoshi, H. Yatsuya, C. Murata, A. Sekiya, K. Wada, H. M. Zhang, K. Matsushita, K. Sugiura, S. Takefuji, P. OuYang, N. Nagasawa, T. Kondo, S. Sasaki and H. Toyoshima (2006). "Eating fast leads to obesity: Findings based on selfadministered questionnaires among middle-aged Japanese men and women." Journal of Epidemiology 16(3): 117-124.

Owen, C. G., P. H. Whincup, L. Orfei, Q. A. Chou, A. R. Rudnicka, A. K. Wathern, S. J. Kaye, J. G. Eriksson, C. Osmond and D. G. Cook (2009). "Is body mass index before middle age related to coronary heart disease risk in later life? Evidence from observational studies." Int J Obes (Lond) 33(8): 866-877.

Paddon-Jones, D., E. Westman, R. D. Mattes, R. R. Wolfe, A. Astrup and M. Westerterp-Plantenga (2008). "Protein, weight management, and satiety." Am J Clin Nutr 87(5): 1558s-1561s.

Pal, S. and V. Ellis (2010). "The chronic effects of whey proteins on blood pressure, vascular function, and inflammatory markers in overweight individuals." Obesity (Silver Spring) 18(7): 1354-1359.

Pliner, P., R. Bell, E. S. Hirsch and M. Kinchla (2006). "Meal duration mediates the effect of "social facilitation" on eating in humans." Appetite 46(2): 189-198.

Pliner, P. and N. Mann (2004). "Influence of social norms and palatability on amount consumed and food choice." Appetite 42(2): 227-237.

Racette, S. B., S. S. Deusinger, M. J. Strube, G. R. Highstein and R. H. Deusinger (2005). "Weight changes, exercise, and dietary patterns during freshman and sophomore years of college." J Am Coll Health 53(6): 245-251. 
Racette, S. B., S. S. Deusinger, M. J. Strube, G. R. Highstein and R. H. Deusinger (2008). "Changes in weight and health behaviors from freshman through senior year of college." J Nutr Educ Behav 40(1): 39-42.

Reedy, J., P. N. Mitrou, S. M. Krebs-Smith, E. Wirfalt, A. Flood, V. Kipnis, M. Leitzmann, T. Mouw, A. Hollenbeck, A. Schatzkin and A. F. Subar (2008). "Indexbased dietary patterns and risk of colorectal cancer: the NIH-AARP Diet and Health Study." Am J Epidemiol 168(1): 38-48.

Reiser, R. (1978). "Oversimplification of Diet - Coronary Heart-Disease Relationships and Exaggerated Diet Recommendations." American Journal of Clinical Nutrition 31(5): 865-875.

Rising, R., D. E. Larson and E. Ravussin (1992). "Do Obese Eat Faster Than Lean Subjects - Food-Intake Studies in Pima-Indians." Clinical Research 40(2): A636A636.

Salvy, S. J., D. Jarrin, R. Paluch, N. Irfan and P. Pliner (2007). "Effects of social influence on eating in couples, friends and strangers." Appetite 49(1): 92-99.

Sasaki, S., A. Katagiri, T. Tsuji, T. Shimoda and K. Amano (2003). "Self-reported rate of eating correlates with body mass index in 18-y-old Japanese women." International Journal of Obesity 27(11): 1405-1410.

Shah, M., J. Copeland, L. Dart, B. Adams-Huet, A. James and D. Rhea (2014). "Slower Eating Speed Lowers Energy Intake in Normal-Weight but not Overweight/Obese Subjects." J Acad Nutr Diet 114(3): 393-402.

Sharma, S. V., J. A. Bush, A. J. Lorino, M. Knoblauch, D. Abuamer, G. Blog and D. Bertman (2008). "Diet and cardiovascular risk in university marching band, dance team and cheer squad members: a cross-sectional study." J Int Soc Sports Nutr 5: 9.

Steinmetz, K. A. and J. D. Potter (1991). "Vegetables, fruit, and cancer. II. Mechanisms." Cancer Causes Control 2(6): 427-442.

Stroebele, N. and J. M. De Castro (2004). "Effect of ambience on food intake and food choice." Nutrition 20(9): 821-838.

Strong, J. P., G. T. Malcom, C. A. McMahan, R. E. Tracy, W. P. Newman, E. E. Herderick and J. F. Cornhill (1999). "Prevalence and extent of atherosclerosis in adolescents and young adults - Implications for prevention from the pathobiological determinants of atherosclerosis in youth study." Jama-Journal of the American Medical Association 281(8): 727-735. 
Tanihara, S., T. Imatoh, M. Miyazaki, A. Babazono, Y. Momose, M. Baba, Y. Uryu and H. Une (2011). "Retrospective longitudinal study on the relationship between 8year weight change and current eating speed." Appetite 57(1): 179-183.

van Horn, L. V., P. Stumbo, A. Moag-Stahlberg, E. Obarzanek, V. W. Hartmuller, R. P. Farris, S. Y. Kimm, M. Frederick, L. Snetselaar and K. Liu (1993). "The Dietary Intervention Study in Children (DISC): dietary assessment methods for 8- to 10-yearolds." J Am Diet Assoc 93(12): 1396-1403.

Vartanian, L. R., C. P. Herman and J. Polivy (2007). "Consumption stereotypes and impression management: how you are what you eat." Appetite 48(3): 265-277.

Veldhorst, M., A. Smeets, S. Soenen, A. Hochstenbach-Waelen, R. Hursel, K. Diepvens, M. Lejeune, N. Luscombe-Marsh and M. Westerterp-Plantenga (2008). "Protein-induced satiety: effects and mechanisms of different proteins." Physiol Behav 94(2): 300-307.

Viskaal-van Dongen, M., F. J. Kok and C. de Graaf (2011). "Eating rate of commonly consumed foods promotes food and energy intake." Appetite 56(1): 25-31.

Wang, Y. and M. A. Beydoun (2007). "The obesity epidemic in the United States-gender, age, socioeconomic, racial/ethnic, and geographic characteristics: a systematic review and meta-regression analysis." Epidemiol Rev 29: 6-28.

WELSH, S., C. DAVIS and A. SHAW (1992). "Development of the Food Guide Pyramid." Nutrition Today 27(6): 12-23.

Willett, W. C., M. J. Stampfer, J. E. Manson, G. A. Colditz, F. E. Speizer, B. A. Rosner, L. A. Sampson and C. H. Hennekens (1993). "Intake of trans fatty acids and risk of coronary heart disease among women." Lancet 341(8845): 581-585.

Wolongevicz, D. M., L. Zhu, M. J. Pencina, R. W. Kimokoti, P. K. Newby, R. B. D'Agostino and B. E. Millen (2010). "Diet quality and obesity in women: the Framingham Nutrition Studies." Br J Nutr 103(8): 1223-1229.

Yeomans, M. R., R. W. Gray, C. J. Mitchell and S. True (1997). "Independent effects of palatability and within-meal pauses on intake and appetite ratings in human volunteers." Appetite 29(1): 61-76. 